\title{
A ORGANIZAÇÃO DAS PRAÇAS DE DESPORTO/EDUCAÇÃO FISICA NA CIDADE DE PORTO ALEGRE (1920 - 1940)
}

Recebido em: 07/01/2010

Aceito em: 17/03/2010

\author{
Maria Luisa Oliveira da Cunha ${ }^{1}$ \\ Janice Zarpellon Mazo ${ }^{2}$ \\ Marco Paulo Stigger ${ }^{3}$
}

Universidade Federal do Rio Grande do Sul - UFRGS

Porto Alegre - RS - Brasil

RESUMO: As praças se afirmaram enquanto espaços de sociabilidade e lazer dos porto-alegrenses a partir de meados dos anos 1920. O objetivo deste estudo é identificar como ocorreu a emergência e difusão das práticas corporais e esportivas nas praças de Porto Alegre nas décadas de 1920 a 1940, e que representações de identidades culturais foram construídas. A análise documental das fontes revelou que a utilização das praças foi privilegiada no que diz respeito à promoção de práticas corporais e esportivas. As denominadas Praças de Desportos se constituíram em espaços para as práticas organizadas dirigidas pelo Serviço de Recreação Pública (SRP) instaurado em 1926. Na transição das décadas de 1930-1940, as competições esportivas foram potencializadas nas praças constituindo-se em um espaço de produção de representações de identidades.

PALAVRAS-CHAVE: Educação Física e Treinamento. História do Esporte. Atividades de Lazer.

\section{THE ORGANIZATION OF THE SPORTS SQUARES/ PHYSICAL EDUCATION IN THE PORTO ALEGRE CITY (1920 - 1940)}

ABSTRACT: The squares had affirmed while sociability and leisure spaces of Porto Alegre city people since 1920 middle. The objective of this study is to identify how it has occurred corporal and sportives practices emergency and diffusion in Porto Alegre city squares betwenn 1920 and 1940 decades, and which identities representations had been constructed. The documentary analysis of the sources disclosed that squares use was privileged for corporal and sportives practices promotion. The called "Squares of

\footnotetext{
${ }^{1}$ Professora Mestre do Departamento de Educação Física da Universidade Federal do Rio Grande do Sul.

${ }^{2}$ Professora Doutora do Departamento de Educação Física e do Programa de Pós-Graduação em Ciências do Movimento Humano da Universidade Federal do Rio Grande do Sul.

${ }^{3}$ Professor Doutor do Departamento de Educação Física e do Programa de Pós-Graduação em Ciências do Movimento Humano da Universidade Federal do Rio Grande do Sul.
} 
Sports" had been constituted in spaces for organized pratices directed by the Public Recreation Service (PRS), introduced in 1926. In the transistion of 1930-1940 decades, the sportives competitions had been potentiated in the squares consisting it as space of identities representations production.

KEYWORDS: Physical Education and Training. Sport History. Leisure Activities.

\section{INTRODUÇÃO}

O presente estudo trata das práticas corporais e esportivas nas praças públicas da cidade de Porto Alegre nas décadas de 1920 a 1940. Embora o surgimento das primeiras praças públicas em Porto Alegre seja datado do final do século XIX, somente no início do século XX estes espaços começaram, gradualmente, a serem ocupados pelos portoalegrenses para a sociabilidade e lazer. As formas de ocupação destas praças foram sendo reformuladas em decorrência das transformações políticas, econômicas e sociais desencadeadas no final do século XIX.

A partir de conseqüências vinculadas à Revolução Industrial, observa-se a disseminação da prática dos lazeres, não apenas no cenário nacional, mas em um quadro ocidental, no qual as diversas camadas sociais passaram a usar, em escala cada vez mais alargada, o tempo livre em diversas práticas culturais. Esta nova situação mundial implicou em outro olhar sobre as praças de Porto Alegre, espaços que, inicialmente, eram destinados apenas aos passeios dos porto-alegrenses. Com a transformação do significado das praças e sua apropriação pela população, outras formas de lazer começaram a emergir, destacando-se as práticas corporais e esportivas.

Foi assim que, em meados dos anos 1920, as práticas corporais e esportivas começaram a tomar lugar nas praças públicas de Porto Alegre. Com a criação do Serviço de Recreação Pública (SRP - 1926) e o incremento das práticas, algumas praças foram denominadas Praça de Desportos; à medida que passaram a ser utilizadas pelas 
escolas, constituindo-se em uma extensão das mesmas, as Praças de Desportos passaram a ser chamadas de Praças de Educação Física, pois começaram a contar com o trabalho de instrutores Educação Física.

Nesse contexto, o objetivo do presente estudo é identificar como ocorreu a emergência e difusão das práticas corporais e esportivas nas Praças de Desportos/Praças de Educação Física de Porto Alegre no período dos anos 1920 a 1940. Deste objetivo central emergem as seguintes questões norteadoras da pesquisa: a) Quais foram as primeiras práticas corporais e esportivas introduzidas nas Praças de Desportos/Praças de Educação Física de Porto Alegre nos anos de 1920 a 1940; b) Que representações de identidades foram construídas nas Praças de Desportos/Praças de Educação Física da cidade de Porto Alegre, através das práticas corporais e esportivas nos anos de 1920 a 1940.

Justifica-se a realização desta pesquisa em razão de se perceber que os estudos que tratam do lazer e da recreação pública em Porto Alegre (AMARAL, 1998; AMARAL, 2001; FEIX, 2003; MAZO, 2004; STIGGER, 1993; WERNECK, 2002), em geral, focalizam o período da segunda metade dos anos 1920, quando iniciaram as atividades recreativas nas praças públicas de Porto Alegre e foi organizado o Serviço de Recreação Pública (SRP). Há uma lacuna no que diz respeito à estruturação das práticas nas praças públicas.

A busca de respostas para essas questões foi desenvolvida através de um estudo que teve como bases a História Cultural, de acordo com o que está apresentado nas páginas que se seguem.

\section{PELO PRISMA DA HISTÓRIA CULTURAL}


A história representando um momento de registro do passado tem recebido um novo olhar no contexto deste milênio. Pesavento (2002) mostra a importância das fontes diversas que podem contar a história dizendo que, se não podemos estar no passado para viver os fatos que já aconteceram temos que nos cercar de formas diversas para reconstruir a história, partindo de um princípio fundamental onde todos os fenômenos envolvidos são entendidos como culturais.

Assim, a História Cultural se afirma buscando a aproximação da verdade reconstruindo os fatos passados, à luz do presente. Esta necessidade da reconstrução histórica vem percorrendo o caminho dos tempos, passando por várias vertentes, apreciando o rompimento e a proposição de paradigmas. Num processo permeado pela descoberta da não existência das verdades absolutas, apresenta-se a possibilidade de valorar a nossa representação dos fatos, a experiência, o conhecimento sobre o assunto e a nossa capacidade de erudição coerente dentro de referencial específico.

Cardoso (1992) afirma que a história por si, já tem sua palavra a dizer, os seus elementos a contribuir à compreensão das estruturas atuais e ao planejamento do futuro, pois que os processos históricos são sempre únicos, mas iluminam em perspectiva as condições comuns a todos eles, ou a certo número. A história é uma narrativa sobre o passado, resultante de um entrelaçamento de objetividade e subjetividade (percepções e olhares diferentes). O conhecimento histórico é uma construção que envolve a subjetividade de quem escreve e a mediação entre o passado (objeto de investigação) e o presente (tempo no qual se escreve), porém, sem o juízo de valor do contexto contemporâneo do historiador.

Mas esta velha história, narrativa, criadora de mitos que cumprem exatamente uma função preservadora das estruturas em vigor, através dos mecanismos de 
hegemonia ideológica foi, em determinado momento, colocada em questão. Abre-se aqui o espaço para vermos surgir à necessidade de que uma nova história, com sua ênfase no coletivo ou no social, consolidem seu espaço.

A História Cultural possibilita decifrar a realidade por meio das suas representações e construir o real de outros tempos acessando os registros e sinais do passado - fontes/documentos. Para Elias (1989), tempo e espaço também devem ser estudados conjuntamente porque estão imbricados. De acordo com ele tempo e espaço são símbolos conceituais de certos tipos de atividades e instituições sociais que permitem aos homens orientarem-se diante de posições ou distâncias entre estas posições que acontecimentos de todo tipo tomam. Portanto, se a proposta é compreender o tempo no contexto onde esse é produzido, deve-se considerar o espaço como relevante na configuração das relações sociais.

Segundo Chartier (1990) o objetivo da nova história cultural é identificar o modo como em diferentes lugares (espaço) e momentos (tempo) uma determinada realidade social é construída, pensada, dada a ler; desta forma, observar a cultura enquanto prática e estudá-la através de categorias como representação e apropriação. Estas categorias dão norte à visão, pois que as práticas possibilitam fazer reconhecer uma identidade social, exibir uma maneira própria de estar no mundo, significar simbolicamente um estatuto e uma posição. As representações do mundo social, embora aspirem à universalidade de um diagnóstico fundado na razão, são sempre determinadas pelos interesses do grupo que as forjam. Daí para cada caso, o necessário relacionamento dos discursos proferidos com a posição de quem os utiliza, sendo também portadoras do simbólico, ou seja, dizem mais do que aquilo que mostram ou 
Maria Luisa O. da Cunha, Janice Z. Mazo e $\quad$ A Organização das Praças de Desporto/Educação Física ... Marco Paulo Stigger

enunciam, carregam sentidos ocultos, que construídos social e historicamente, se internalizam no inconsciente coletivo e se representam como naturais.

Burke (2005) esclarece que um dos paradigmas da nova história cultural é o estudo das práticas. Isto se dá nos estudos das últimas décadas, ressaltando, contudo, que ocorreram poucas inovações de método, no sentido estrito do termo, porém muitos novos temas foram descobertos e explorados com a ajuda de novos conceitos. Ao buscarmos como se dá certa construção social e suas representações nos depararemos com circunstâncias que podem dar significado abrangente as práticas atuais.

Nesta pesquisa partimos do entendimento de que toda atividade humana produz história, pois tudo tem um passado que pode, em princípio, ser reconstruído e relacionado ao restante do passado. Para transitar pela história cultural que este passado nos revela na cidade de Porto Alegre nas décadas de 1920 a 1940 vamos referendar nossos discursos com os autores Roger Chartier e Peter Burke e, para tratar do aparecimento de "modernas" práticas de lazer, seu significado e dimensão social, dialogamos com Norbert Elias.

O trabalho de Elias (1992) permite, em especial, articular as duas significações do termo cultura, a primeira designando as obras e os gestos que, em uma sociedade, estão ligados ao julgamento estético ou intelectual. A segunda refere-se às práticas ordinárias, "sem qualidades", que tecem a trama das relações quotidianas e exprimem a maneira como uma comunidade, em um determinado tempo e lugar, vive e reflete sua relação com o mundo e a história. Pensar historicamente as formas e as práticas culturais é, portanto, necessariamente elucidar as relações alimentadas por essas duas definições. 
Burke (2005) afirma que esta direção aos estudos das práticas ampliou, por exemplo, os estudos da teologia para a história das práticas religiosas, da lingüística para a história da fala e da teoria científica para a história do experimento. Dessa maneira, até as práticas mais cotidianas, como a leitura, a alimentação, o vestuário, a habitação e os esportes transformaram-se em campos férteis de investigação por parte dos historiadores da História Cultural.

Entretanto, não só pelo prisma das práticas que Elias sustentará nosso discurso. O aparecimento de novas formas de lazer deve ser entendido à luz do processo civilizador dos costumes, de acordo com Elias e Dunning (1992). Isto é, para entendermos a natureza das práticas predominantes de recreação e divertimento, seu significado e dimensão social, é necessário entender como o processo civilizatório atuou sobre as necessidades e hábitos de lazer na sociedade moderna. O processo civilizador reflete, em poucas palavras, o desenvolvimento de normas de conduta social que inibem as demonstrações espontâneas de emoções; conformando hábitos culturais civilizados e padrões de relacionamento que são internalizados pelos indivíduos e reproduzidos. O desenvolvimento do autocontrole dos impulsos molda uma segunda natureza nos indivíduos, forjada pela ação de instituições civilizatórias, como a família, a escola, a empresa, o clube social, etc. (ELIAS, 1994).

O avanço deste processo está associado à mudança no estilo de vida operante, e nas diversas configurações sociais existentes. Tais mudanças que se processaram na civilização ocidental ao longo dos últimos séculos estiveram relacionadas com o desenvolvimento de formas de controle social mais eficaz e favoreceram o surgimento de uma gama de opções de entretenimento como, por exemplo, as práticas corporais e 
esportivas nas praças, as quais se difundiram com maior êxito à medida que os indivíduos desenvolveram mecanismos de domínio sobre os seus instintos e emoções.

Para Elias \& Dunning (1992), as modernas atividades de lazer liberam as tensões provenientes do estresse diário ao mesmo tempo em que permitem manifestações intensas de sentimentos, contudo, sem ameaçar a integridade física e moral das pessoas e sem afrontar a ordem estabelecida. Para estes autores as práticas de lazer apresentam três formas elementares de ativação emocional: sociabilidade, mobilidade e imaginação. Para eles, invariavelmente pelo menos uma destas três formas elementares estará associada a sua prática.

As noções de "práticas" e "representações" as quais são primordiais para o historiador da cultura são explicitadas por Chartier (1990). De acordo com este horizonte teórico, a cultura (ou as mais diversas formações culturais) poderia ser examinada no âmbito produzido pela relação interativa entre estes dois pólos. Tanto os objetos culturais seriam produzidos entre práticas e representações, como os sujeitos produtores e receptores de cultura circulariam entre estes dois pólos.

A representação acrescenta Chartier (1991), inserem-se em um campo de concorrências e de competições cujos desafios se enunciam em termos de poder e de dominação; em outras palavras, são produzidas verdadeiras lutas de representações. E estas lutas geram inúmeras apropriações possíveis das representações, de acordo com os interesses sociais, com as imposições e resistências políticas, com as motivações e necessidades que se confrontam no mundo humano.

Ao trabalhar sobre as lutas de representação a história cultural opera um retorno hábil também sobre o social, pois centra a atenção sobre as estratégias simbólicas que determinam posições e relações e que constroem, para cada classe, grupo ou meio, um 
ser-percebido constitutivo de sua identidade. Dessa forma, pode-se pensar uma história cultural do social que tome por objeto a compreensão das formas e dos motivos - ou, por outras palavras, das representações do mundo social - que, à revelia dos atores sociais, traduzem as suas posições e interesses objetivamente confrontados e que, paralelamente, descrevem a sociedade tal como pensam que ela é, ou gostariam que fosse.

Surgem então as tentativas para decifrar as sociedades, penetrando nas meadas das relações e das tensões que as constituem a partir de um ponto de entrada particular (um acontecimento, importante ou obscuro, um relato de vida, uma rede de práticas específicas). Considerando não haver prática ou estrutura que não seja produzida pelas representações, contraditórias e em confronto, pelas quais os indivíduos e os grupos dão sentido ao mundo que é o deles, nosso ponto de entrada particular é, neste estudo, as práticas corporais e esportivas nas praças e parques públicos de Porto Alegre nas décadas de 1920 a 1940.

As diferentes práticas corporais institucionalizadas têm chamado a atenção de cientistas sociais e historiadores como objetos que podem contribuir para ampliar nosso olhar sobre o contexto social em que se inserem. Entre tantos, Norbert Elias (1992) dirigiu às praticas corporais e esportivas um olhar privilegiado, reconhecendo sua relevância no quadro cultural da modernidade e contemporaneidade.

Muito diferente dos "retratos" relativamente estatísticos de épocas inteiras, Peter Burke (2005) considera que é possível escrever a história cultural de uma forma narrativa. O desafio é efetuar esse procedimento sem oferecer à história um enredo triunfalista. Desse modo, narrativas complexas, expressando multiplicidades de pontos de vista, norteadas por uma problemática, possibilitam tornar inteligíveis os conflitos. 
Na mesma perspectiva do autor, neste trabalho a nossa narrativa será centrada na preocupação em analisar os contextos socioculturais que envolvem as pessoas comuns, salientando as maneiras pelas quais elas aplicavam sentido às suas práticas e mundos nas praças públicas de Porto Alegre.

\section{PROCEDIMENTOS METODOLÓGICOS}

Os procedimentos adotados consistem na coleta e análise de fontes impressas através da analise de conteúdo (BARDIN, 1977; TRIVIÑOS, 1992). A análise de conteúdo é uma operação ou um conjunto de operações visando representar o conteúdo de um documento sob uma forma diferente da original, a fim de facilitar num estado ulterior, a sua consulta e referência. Enquanto tratamento da informação contida nos documentos acumulados, a análise tem por objetivo dar forma conveniente e representar de outro modo essa informação, por intermédio de procedimentos de transformação.

Um documento é qualquer material escrito que possa ser usado como fonte de informação sobre um assunto. A pesquisa documental é uma modalidade de coleta de dados que apresenta algumas vantagens, conforme Ludke \& Andre (1986): o baixo custo, ser fonte não reativa (permite acesso onde não se pode contatar o sujeito) e não se alterarem no meio da pesquisa. É usada quando os dados são problemáticos e para validar e ratificar informações e não é neutra, pois a escolha dos documentos nunca é totalmente aleatória.

Para o desenvolvimento desse estudo, a pesquisa documental percorreu diversas fontes históricas sobre as praças e parques públicos na cidade de Porto Alegre no período de 1920 a 1940, como o Catálogo da Revista do Globo, diversos jornais portoalegrenses, o Almanaque Esportivo do Rio Grande do Sul, manuscritos e álbuns de 
fotografias encontrados no Centro de Memória do Esporte (CEME) da ESEF/UFRGS, documentos, mapas e plantas baixas, projetos arquitetônicos e legislação que passamos a contemplar individualmente a partir de agora.

A escolha da Revista do Globo, meio de comunicação impresso editado pela Livraria Editora Globo em Porto Alegre no período de 1929-1967 utilizada como fonte de pesquisa deve-se a ênfase dada aos esportes desde sua primeira edição em 1929, em seção a eles dedicada, além de publicar no ano de 1933 um número especial sobre as práticas esportivas. Esta revista está digitalizada e divulgada em formato de CD-ROM disponível para pesquisa (MAZO, 2004). Cabe salientar que vários autores (MOTTIN, 1996; THORSTENBERG, 1998; TORRESINI, 1999; CASTRO, 1999; GOMES, 2001; SOARES, 2001; DALMÁZ, 2001; MAZO, 2004; SILVA, 2008) já subsidiaram suas pesquisas neste acervo denotando sua importância e riqueza de informações sobre os assuntos ligados especialmente à cultura local e regional.

Outra fonte de consulta foi o Almanaque Esportivo do Rio Grande do Sul, organizado por José Ferreira Amaro Júnior, que foi publicado no período de 1942 a 1959. Encontramos vários exemplares à disposição na biblioteca da Escola de Educação Física da Universidade Federal do Rio Grande do Sul com algumas reportagens dedicadas as Praças de Desportos/Praças de Educação Física.

Além das fontes históricas mencionadas anteriormente subsidiaram esta pesquisa as dissertações, monografias, teses, livros e outros documentos que contribuíram para o aporte teórico e análise dos dados da investigação.

Ainda consultamos o acervo do CEME/ESEF/UFRGS, a documentação do Museu da Comunicação Social Hipólito Jose da Costa e do Arquivo Histórico de Porto Alegre Moyses Vellinho, onde os materiais registrados e organizados nestes locais 
deram o perfil inovador na descoberta dos detalhes da história. O CEME da ESEF/UFRGS é, sem dúvida, um lugar privilegiado para os pesquisadores da história do esporte e da educação física. O material catalogado sobre recreação pública advém em grande parte de doações de familiares dos personagens envolvidos neste momento histórico da cidade de Porto Alegre, ou ainda de documentos da própria Escola de Educação Física.

Seguramente abrir gavetas e folhear álbuns antigos ${ }^{4}$, ler documentos manuscritos, certas vezes inclusive decifrando caligrafias, evoca uma magia de voltar no tempo em um momento que só é permitido ao pesquisador que se permite estar ao pó. Trata-se de um processo de garimpagem onde os documentos precisam ser encontrados, extraídos das prateleiras, das gavetas, dos álbuns, para receber um tratamento que, orientado pelo problema proposto pela pesquisa, estabeleça a montagem das peças, como num jogo de quebra-cabeça.

Encontramos no CEME uma riqueza de informações novas que precisavam ser descobertas para que o grande quebra-cabeça a que nos submetemos montar, iniciando a pesquisa, pudesse ser construído. Este quebra-cabeça montado produziu uma versão da história. Mas como algumas peças teimaram em ficar escondidas e outras não encaixaram por completo, descobrimos pelo caminho que o "jogo" continua.

\footnotetext{
${ }^{4}$ Existe neste acervo um álbum que traz uma série de recortes dos jornais da época da cidade de Porto Alegre, do Brasil e também do exterior (Uruguai, Estados Unidos), onde o professor Frederico Guilherme Gaelzer registrou, através destes recortes de artigos de jornais, o seu trabalho. Os jornais encontrados nestes recortes foram A Noticia, o Correio do Povo e a Ultima Hora (atual Zero Hora), que geralmente destacavam notícias sobre as praças e as mudanças em sua infra-estrutura. Esta ênfase dada pelos jornais auxiliou na reconstrução e no entendimento das fases por que passou a cidade de Porto Alegre, e especialmente as praças como espaços de lazer, do ponto de vista de suas alterações arquitetônicas e dos significados a ela atribuídos. Este álbum foi doado ao CEME/ESEF/UFRGS por Lenea Gaelzer, filha do professor, juntamente a um vasto material pessoal com fotos, documentos e plantas arquitetônicas que se referiam ao trabalho executado pelo Professor Gaelzer na cidade de Porto Alegre e nos países onde estudou e trabalhou. Ele não possui registro catalográfico e por este motivo a partir deste momento o citaremos como Álbum de artigos do acervo do CEME/ESEF/UFRGS
} 


\section{AS PRAÇAS DE DESPORTOIEDUCAÇÃO FÍSICA EM PORTO ALEGRE}

A fisionomia da cidade de Porto Alegre, alterada em função das intervenções urbanas, transformou-se com a destinação de espaços públicos às atividades de lazer para a população porto-alegrense. Através do planejamento urbano, obras de saneamento, alargamento de ruas, embelezamento da cidade, construção de prédios públicos, praças e parques, constatamos a preocupação, por parte das autoridades da Intendência, então governo municipal, de melhorar as condições de vida da população, destacando a construção de algumas praças ou a apropriação de outros espaços públicos para fins de lazer. Em algumas destas praças públicas de Porto Alegre foram promovidas práticas corporais e esportivas organizadas à semelhança do que já ocorria nos clubes esportivos da cidade.

Isso ocorria na media em que a necessidade e o interesse de investimento institucional em educação, esporte e recreação eram prementes, influenciados pelo movimento de educação física mundial, que poderia ser um meio de prevenção da delinquência juvenil. Além disto, a demanda de trabalhadores para a prática de esporte que se popularizava pela conquista de maior tempo livre e a preocupação com as crianças que careciam de lugar público para brincar davam às praças status de lugar adequado para este fim. Então os espaços deveriam ser dotados de equipamentos apropriados e recursos humanos que organizassem as práticas corporais e esportivas que ali seriam desenvolvidas. As relações sociais se desenrolariam nestes espaços no tempo livre do trabalho e a importância de direção para estas ocasiões e para as ações que seriam realizadas começaram a despertar na municipalidade a intenção de controle.

Elias (1989) refere que tempo e espaço devem ser estudados conjuntamente porque estão imbricados. Então é necessário compreender o tempo no contexto onde 
esse é produzido, devendo-se considerar o espaço como relevante na configuração das relações sociais. As praças tornavam-se os espaços para o tempo livre e a direção das ações nestes espaços aparece como função inerente à municipalidade. Nessa direção foi criado o "Serviço de Recreação Pública" pela Prefeitura Municipal de Porto Alegre em 1926.

O Serviço de Recreação Pública foi idealizado pelo Prof. Frederico Guilherme Gaelzer $^{5}$, então, primeiro inspetor de Educação Física da Diretoria Geral da Instrução Pública do Estado do Rio Grande do Sul. O Prof. Gaelzer é considerado o pioneiro na institucionalização da recreação pública na cidade de Porto Alegre, pois programou e implantou os Jardins de Recreio, também chamados de Praças de Recreio, em algumas praças públicas da cidade. Além disso, cabe destacar que quando foi criada, em 1940, a primeira instituição de ensino superior em educação física no Rio Grande do Sul - a Escola Superior de Educação Física - foi professor pioneiro e atuou como diretor desta instituição no período de 28/9/1955 a 24/2/1959 (GUTIERREZ,1971).

Para Macedo (1973) Gaelzer foi um grande divulgador da recreação e dos esportes em Porto Alegre. Com a experiência acumulada, inclusive como integrante do Departamento Estadual de Educação Física, fundado em 1939, o Prof. Gaelzer foi um precursor da recreação pública no Estado e até mesmo no país. Ele definiu diretrizes

\footnotetext{
${ }^{5}$ Professor Frederico Guilherme Gaelzer nasceu em Novo Hamburgo, então município de São Leopoldo, no Rio Grande do Sul, em 29 de Julho de 1897. Em 1910, fez a formação primária em São Leopoldo e o curso secundário em Berlim, na Alemanha. Quando retornou ao Brasil atuou como atleta da Associação Cristã de Moços (ACM) de Porto Alegre em 1918. No ano seguinte viajou para os Estados Unidos para estudar na Universidade de Chicago, onde se graduou em Educação Física, recebendo o título de Máster of Science em Educação Física e Recreação. Após receber o diploma, em 1921, passou a atuar como professor na Universidade de Chicago. Retornou ao Rio Grande do Sul em 1923, mas permaneceu pouco tempo, deslocando-se para estudar e trabalhar na ACM de Montevidéu no Uruguai. Na ACM trabalhou com basquetebol e participou dos programas de recreação pública. Após um ano de permanência no Uruguai, em 1924 voltou a residir em Porto Alegre. Na cidade, em 1926 iniciou pesquisa sobre o levantamento de áreas livres com vistas a um futuro atendimento da população em praças, através da prática esportiva e recreação pública. Concluído o levantamento solicitado pela Intendência de Porto Alegre foi nomeado para trabalhar na Intendência a partir de agosto de 1926. Ainda neste ano criou o "Systema de Jardins de Recreio" nas praças da cidade. Faleceu em $1^{\circ}$ de Setembro de 1972 (FEIX, 2003; MAZO, 2005).
} 
para as atividades nas praças públicas, particularmente direcionadas as práticas corporais e esportivas nos chamados Jardins de Recreio.

Devemos ressaltar que nos documentos consultados encontramos as praças públicas, onde se instalaram os Jardins de Recreio, nomeadas como Praça de Desporto. Entendemos que isto ocorria, pois o Serviço de Recreação Pública tinha em sua concepção atingir um grande público para as atividades corporais, quer recreativas ou esportivas, incluindo nestas das crianças aos idosos. Assim, nos primeiros anos da instalação dos Jardins de Recreio e sua ênfase nas práticas recreativas, as reportagens dos jornais da época utilizavam esta nomenclatura para tratar destes espaços. Com as práticas esportivas tomando vulto as citações passam a referir-se as Praças de Desportos. Neste trabalho vamos tratá-las conforme as encontramos referidas nos documentos consultados, respeitando esta linha do tempo e também a linha de ações nelas desenvolvidas.

O primeiro Jardim de Recreio instalado na Praça $n^{o} 1$ - Praça de Desportos General Osório, também conhecida como Praça do Alto da Bronze, visava a prática de atividades recreativas direcionadas (WERNECK, 2002; FEIX, 2003). Nesta praça foram improvisadas as mais rudimentares aparelhagens, como por exemplo, pneus velhos amarrados em árvores constituindo um meio de recreação para crianças (FEIX, 2003). Sobre estes artefatos improvisados registra o professor Gaelzer em um dos relatórios da época encontrado no acervo do CEME/ESEF/UFRGS:

Os primeiros instalados foram presos as arvores, sendo aproveitados pneus usados e alguns aparelhos que já possuíamos em deposito no almoxarifado. Aos poucos, porém foram estes substituídos, adquirindo-se outros mais modernos e efficicientes, o que veio contribuir para um accrescimo considerável da affluencia de creanças e rapazes (Álbum de artigos do acervo do CEME/ESEF/UFRGS, s/d). 
Em fevereiro de 1927 foi instalado o segundo Jardim de Recreio na Praça de $n^{o}$ 2 - Pinheiro Machado, conforme Decreto-Lei no 88 de 19/02/1927, situada no arraial (atualmente bairro) de São João. Este era o Jardim de Recreio mais freqüentado pelos porto-alegrenses, provavelmente em razão da sua localização privilegiada, como também pela inexistência de cerca. Anos depois, com a introdução de alguns melhoramentos nos equipamentos e para o controle da frequiência dos usuários pelos zeladores que fiscalizavam a área foi colocada uma cerca demarcando uma única entrada na praça, conforme já havia ocorrido no Jardim de Recreio $n^{\circ} 1$.

Os Jardins de Recreio na Praça $n^{o} 3$ - Florida e na Praça $n^{o} 4$-Dr. Montaury, foram instalados na sequência sob a orientação técnica do professor Gaelzer. O professor Gaelzer deixou registrado muito de suas realizações em textos, diários e publicações de jornais, possibilitando que hoje pudéssemos ler o passado e conhecer, na versão dele, como aconteceu a institucionalização destes lugares de lazer. Entre esses, encontramos no acervo do CEME/ESEF/UFRGS, a planta baixa do primeiro Jardim de Recreio na Praça General Osório ou Praça do Alto da Bronze, na qual está assinalada a disposição dos brinquedos infantis, quadras esportivas, e vegetação existente, demonstrando a organização que se submetia a praça que abrigaria o Jardim de Recreio. Esta planta traz o registro da Secretaria Municipal de Obras e Viação (SMOV) com descrição da vegetação local e a localização das quadras de vôlei e basquete, brinquedos, área de descanso e prédio para o Jardim da Infância. 


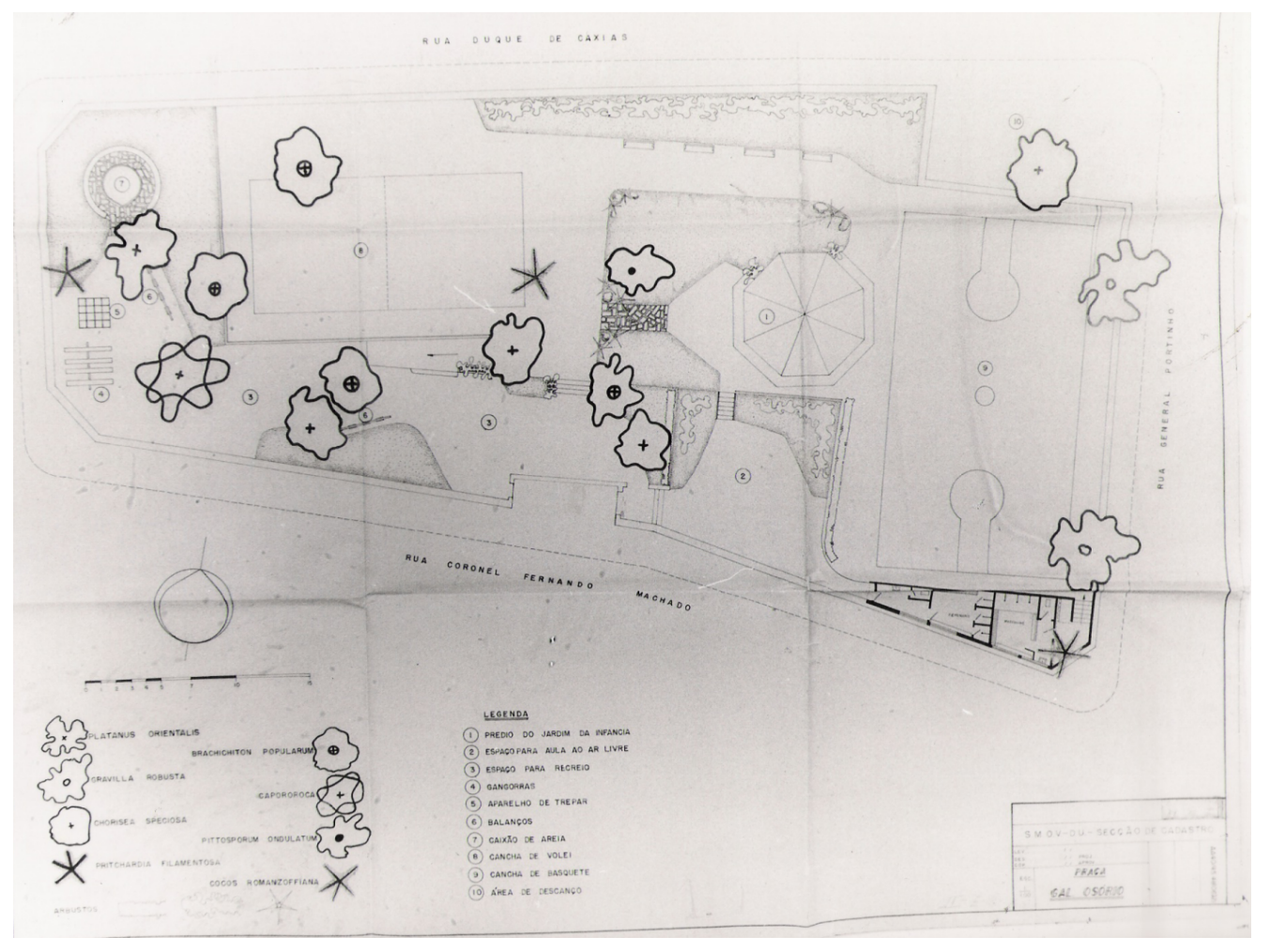

FIGURA 1 - Planta baixa do primeiro Jardim de Recreio na Praça de Desportos General Osório, s /d. Fonte: Arquivo do CEME /ESEF/UFRGS. Pasta-arquivo sob título Recreação Pública.

Ao que parece, talvez por serem desconhecidos os fins a que se destinavam espaços públicos dessa natureza, conforme os relatos registrados havia certa dificuldade para conseguir uma frequência "seleta"; porém aos poucos, e com a divulgação de regulamentos internos, foram atingidos os objetivos de trazer aos jardins as crianças e os jovens a quem esses espaços se destinavam.

Em relação a esta organização e padronização dos espaços para recreação pública encontramos em planta, a lista mínima dos brinquedos para um parque infantil de um Jardim de Recreio enumerando seis brinquedos que fariam a composição deste espaço. Com tamanhos exatos e medidas para sua reprodução os balanços para meninas e para bebês, as gangorras, escorregadores, o passo do gigante e um aparelho de 
ginástica foram descritos como modelo alertando para a padronização que se buscava nos materiais utilizados para as atividades desenvolvidas nestes jardins.

Assim, os primeiros Jardins de Recreio e Praças de Desportos foram doados a população, mas logo necessitaram de um controle e organização que ficou subordinado á direção dos municípios. Com o decorrer do tempo, as formas de controle e organização foram aprimoradas por especialistas no assunto, passando os Jardins de Recreio a contar com espaços delimitados e aparelhagens adequadas para as práticas corporais e esportivas.

Em 30 de Dezembro de 1928 é noticiada a criação do Jardim de Recreio da Praça de Desportos $n^{o} 4$ - José Montaury, com ênfase para a qualidade atingida em pouco tempo de implantação do serviço. Esta praça tinha uma aparelhagem moderna, localização privilegiada e ótimo espaço físico para práticas corporais e esportivas diversas, conforme podemos perceber na citação abaixo:

Dividir-se-á em secções masculina e feminina, tendo cada uma dellas pavilhões, canchas e apparelhos gymnasticos. Este como dissemos, localizado na zona da Independência e Moinhos de Vento virá proporcionar uma recreação sadia aos jovens dessa parte da cidade. Nas suas três canchas de tennis, basket-bal, volley-ball, base-ball, chuveiros e demais installações encontrarão todos o sufficiente com que occupar-se (Álbum de artigos do acervo do CEME/ESEF/UFRGS, s/d).

Sobre a organização dos trabalhos nas praças, em relatório realizado pelo

Professor Gaelzer e direcionado ao Intendente em exercício, encontramos a descrição das atividades nestes espaços. Previa-se, então, atendimento a todas as idades:

Pela manhã, das $6 \mathrm{~h}$ às $7 \mathrm{~h} 30 \mathrm{~min}$, as pessoas idosas tem oportunidade de fazer os seus exercícios físicos; das $8 \mathrm{~h}$ às $11 \mathrm{~h}$ funcionará, sob a orientação de uma professora, o Jardim de Infância para as crianças menores de 12 anos. Neste recanto infantil aparelhado com tanque de patinar, balanços, gangorras, trapézios e argolas, acontecem os jogos para os menores que ainda não freqüientam as escolas. À tarde, das $15 \mathrm{~h}$ às $18 \mathrm{~h}$, os escolares que já estiverem livres de suas tarefas procuram as praças e começa então nova fase de 
atividades no Jardim de Recreio. Nos gramados e nas quadras de voleibol, o instrutor organiza jogos que unindo os jovens da mesma idade exalta o congraçamento das equipes. A partir das $18 \mathrm{~h}$, com o encerramento do trabalho no comércio, a praça volta suas atividades aos que até esta hora trabalham, pois com o encerramento das fabricas e casas comerciais, começa a afluência dos trabalhadores que aproveitam as últimas horas do dia em atividades voltadas a competição entre os times existentes na praça, ora em torneios com os frequientadores das outras praças (Álbum de artigos do acervo do CEME/ESEF/UFRGS, s/d).

No contexto desta experiência institucional deflagrada em Porto Alegre, os significados de recreação foram construídos em estreita relação com a educação física e o esporte, em consonância com a política social e urbana propagada na época. Neste percurso, o Serviço de Recreação Pública preocupou-se, sobretudo, com a massificação das atividades físicas nos Jardins de Recreio, logradouros públicos destinados a promover a formação física, social e moral da população. Além disso, a recreação, tendo como matriz de pensamento principalmente a educação física, foi entendida como sinônimo de atividades físicas e culturais diversas. Essas atividades integravam, na visão das lideranças políticas, um programa completo de educação física. Neste trajeto, a recreação também foi vista como uma metodologia de trabalho diferenciada para a educação física fosse ela desenvolvida no âmbito do ensino formal ou da educação extra-escolar (GOMES, 2003).

Interessante ressaltar que observamos a proximidade de localização dos Jardins de Recreios com as escolas, sendo que os primeiros aparecem como uma extensão dos objetivos de formação dos espaços educacionais nos espaços de lazer. Os quatro Jardins de Recreio construídos até o final dos anos 1920 estavam localizados próximos de escolas como refere à citação a seguir:

Assim é que o jardim de recreio $\mathrm{n}^{\circ} 1$ situado na Praça General Osório, faz frente ao Colégio Fernando Gomes e dista somente quatro quadras da Escola Normal do Gymnasio Anchieta do Colégio Nossa Senhora do Rosário e do Colégio Elementar. O jardim de recreio $n^{\circ} 2$ localizado na Praça General Pinheiro Machado fica ao lado do Colégio e Seminário Evangélico e a duas 
quadras do Colégio Metodista. O jardim de recreio $n^{\circ} 3$ que ocupa a Praça Florida fica ao lado do futuro Colégio da Cooperativa dos empregados da viação férrea. O jardim de recreio no 4 , também denominado Dr. Montaury, dista somente uma quadra do Colégio Nossa Senhora do Bom Conselho, duas quadras do Colégio Espírito do Nazareno e a quatro quadras do Colégio Porto Alegre e da Instituição Pia Chaves Barcellos (Álbum de artigos do acervo do CEME/ESEF/UFRGS, s/d).

E é assim que a Praça de Desportos passou a ser vista em função da valorização da Educação Física, como complemento da escola, a qual estava fortemente unida, pois foi transformada em Praça de Educação Física. O programa de Educação Física da escola e o da praça obedecia a mesma orientação e, tendo o mesmo fim, foram fundidos num único. As praças mantinham ligação íntima com a escola. Eram locais espaçosos, que tinham um programa e proporcionavam aos frequientadores alegria pela prática de jogos e atividades ao ar livre.

Em palestra proferida pelo Professor Gaelzer (1975), encontramos a afirmação de que os Jardins de Recreio eram freqüentados, diariamente, por mais de mil pessoas, e que a média de freqüência mensal era de 25.000 crianças e jovens, distribuídos em turmas. Nos documentos pesquisados no CEME/ESEF/UFRGS, encontramos registros da freqüência destas praças em gráficos e tabelas.

Em documento dirigido ao Sr. Acylino Carvalho, Diretor Geral de Obras e Viação, no qual não consta a autoria, encontramos relatório sobre os Jardins de Recreio que acreditamos ter sido redigido pelo Professor Gaelzer. Ressaltamos a seguir trecho que trata do controle de frequiência, registro dos participantes assíduos nos dois primeiros Jardins de Recreio inaugurados em Porto Alegre:

Tenho o prazer de apresentar-vos o relatório dos serviços e movimento dos Jardins de Recreio que há quasi um anno se vêm construindo nesta Capital por ordem do Sr. Dr. Intendente [...] Para facilitar a fiscalização temos todos os freqüentadores assíduos registrados e classificados em categorias. A secção feminina está dividida em meninas e moças e a secção masculina em três categorias: meninos (de 12 a 14 anos), rapazes (15 a 17) e moços (18 a 
25). Apesar de apenas um ano de funcionamento destes jardins torna-se digno de nota o cavalheirismo com que se batem as diversas turmas (Álbum de artigos do acervo do CEME/ESEF/UFRGS, s/d).

As Praças de Recreio corresponderam às expectativas do município, verificandose em todas elas, segundo os registros encontrados, grande freqüência. Justamente, a estas construções das relações cotidianas influenciadas pelas práticas habituais, das rotinas, que queremos chamar atenção. A afluência citada nos relatórios nos leva a ver um nível de integração social que se dava nos espaços da praça alimentados por sua organização, estrutura e processos.

Elias destaca a necessidade de a análise passar gradativamente da perspectiva da ação para a função. $\mathrm{O}$ autor alerta que o conceito de função não deve ser interpretado como uma expressão de desempenho de uma ação unitária, mas sim como um termo que deve ser compreendido de forma relacional, principalmente com o poder (ELIAS, 1992). Com o desenvolvimento e as transformações ocorridas no processo de modernização da cidade de Porto Alegre podemos observar mudanças no estilo de vida imperante e nas configurações sociais existentes relacionadas diretamente com o controle social eficaz das massas. Este cenário favorecia o surgimento das opções civilizadas e controladas de entretenimento e lazer.

As Praças de Desporto foram símbolo de organização e controle já que no desenrolar das atividades consolidavam-se estes mecanismos. A oferta do lazer como ação existia, e sua função era controladora. Nota-se, pois que os próprios hábitos de lazer na cidade suplantavam os antigos que foram sendo substituídos como, por exemplo, as festas populares pelo baile dançante no clube, a sessão do circo de rua pela matinê no cinema, com evidências de um autocontrole mais efetivo dos indivíduos durante o convívio social no lazer. 
Das praças existentes, quatro já possuíam aparelhamento completo, proporcionando, não só aos jovens como às crianças, horas de recreação e, ao mesmo tempo, de prática corporal e esportiva.

No ano do segundo aniversário da instalação da Praça de Desportos General Osório foi realizada uma solenidade no dia 16 de Agosto de 1929 em comemoração ao sucesso do projeto pioneiro, conforme consta em um convite encontrado no acervo do CEME/ESEF/UFRGS. Em situações como essa, a organização de eventos sociais servia para aproximar e fortalecer os vínculos existentes entre os frequentadores da praça. Os organizadores comemoravam os aniversários de um projeto de sucesso e a experiência dos Jardins de Recreio em Porto Alegre ganhava defensores também nos jornais da cidade. Exemplo disso foi o tratamento dado a um problema suscitado pela prisão de uma quadrilha de meninos de 11 a 15 anos, aos quais a policia soltou por não saber que destino dar-lhes. Em coluna assinada por Eula K. Long, o jornal Diário de Noticias aborda a importância dos espaços públicos de lazer e apresenta as praças como uma medida para evitar o desvio de conduta e a delinquência juvenil:

Esse deverá interessar bastante a nós, os de Porto Alegre, e alegrar-nos o saber que já temos em mãos o principio daquillo que poderá tornar-se um poderoso factor para a preservação da nossa juventude. [...] Aproveitamos, pois, a experiência desses grandes centros, que vêem nas suas praças de recreio, devidamente dirigidas, não um luxo ou um ornato da cidade, mas sentinellas e guias que protegem a juventude do paiz contra os inimigos da sua ordem e sua moral. Oxalá a mesma convicção se arraigue nas mentes dos nossos dirigentes! (Álbum de artigos do acervo do CEME/ESEF/UFRGS, $\mathrm{s} / \mathrm{d})$.

A Revista do Globo, em uma matéria especifica sobre as Praças de Desportos/Educação Física, ressalta a importância da recreação pública gratuita como parte integrante na vida dos povos civilizados. Pondera que a Praça de Educação Física, funcionando ao lado da escola, a qual era considerada elemento indispensável, servia 
nas horas em que esta não funcionava, de centro de recreação pública da juventude e ponto de reunião social de adultos do bairro. No texto era referido que, passando o intervalo das aulas numa praça destas, as crianças teriam verdadeiros tempos de reparação física proporcionando um recreio ordenado e produtivo. E, além disto, não só as crianças e jovens se beneficiariam deste espaço como podemos ver na publicação citada: "o homem hodierno póde, nas horas de lazer, fugir ao bulício da cidade e entregar-se a uma sadia recreação que lhe retempere o corpo e a alma para prosseguir na luta pela vida" (REVISTA DO GLOBO, 11 de Setembro de 1937, s/pag. ${ }^{6}$, apud MAZO, 2004).

Propagando o desenvolvimento de normas de conduta social que inibiam as demonstrações espontâneas de emoções, conformando hábitos culturais civilizados e padrões de relacionamento que eram internalizados pelos indivíduos logo depois de reproduzidos, as Praças de Desportos eram vistas como espaços de controle social eficaz através da mudança de estilo de vida impulsionada pela modernidade. A sociedade moderna reservou para o lazer a satisfação da necessidade que os indivíduos têm de experimentar em público a explosão de fortes emoções, sem com isso perturbar ou colocar em risco a organização da vida social. As rotinas das práticas corporais e esportivas nas praças garantiam este nível elevado de segurança aos indivíduos e as instituições possibilitando a integração e formando uma rede de ligações.

Foram localizados mapas da cidade de Porto Alegre datados de 1932 no acervo do Museu Moysés Velhinho, onde tivemos oportunidade de observar as áreas especificas para a recreação, demarcada já naquele no período. Estas áreas aparecem divididas em Praças de Educação Física, campos de futebol, estádios, clubes de remo,

\footnotetext{
${ }^{6}$ MAZO, J. Catálogo do Esporte e da Educação Física na Revista do Globo (1929-1967). Porto Alegre: PUCRS, 2004, CD-ROM.
} 
praias para banho, áreas de recreação e jardins públicos. Evidencia-se que um grande espaço da cidade estava voltado para o lazer e a recreação, e que através do Serviço de Recreação Pública era administrado e gerenciado para continuar o processo de padronização e inserção da cultura do lazer na cidade de forma organizada.

O fato de que o núcleo do projeto de modernização urbana estivesse centrado sobre a criação de praças, abre o espaço para que as práticas instituídas nestes espaços se afirmem. Constatamos a caminhada progressiva para instaurar a prática recreativa na cidade de Porto Alegre quando vemos que em um dos mapas analisados, datado de 1932, dez praças já estavam em funcionamento, uma em construção e duas em projeto. Observamos que, pela ordem, as praças foram criadas, ocupadas e por serem organizadamente utilizadas pelo serviço de recreação pública, incitaram a criação de novas praças.

Até o presente momento constatamos as manifestações positivas das ações nas Praças de Desportos/Educação Física para o lazer das crianças, jovens e adultos que nela participavam das atividades dirigidas e orientadas. Porém, a manutenção destes espaços com o passar dos anos deixou de ser prioridade municipal, como podemos observar em uma carta enviada ao Diário de Noticias (s/d) endereçada a secção "A Cidade" com um relato do abandono em que se achavam as praças. A carta relata ações de depredação, como o arvoredo que recentemente fora plantado em volta da Praça Florida e que estava quase todo destruído pela falta de cuidado, assim como o desaparecimento de quase todo o gradil em torno desta praça. Na mesma carta, ressalta o autor que era um contraponto ao fim a que foi criada e também a intenção do prefeito Octavio Rocha que viabilizou sua instalação e acreditou estar dotando a capital de um 
melhoramento proveitoso para a infância, proporcionando-lhe de um modo eficaz de desenvolvimento físico e que pela falta de cuidado, ia ficando ao abandono.

Os gastos para sua criação, mais de 500 contos de réis, e para manutenção com funcionários (superior a um conto de réis por mês) também são mencionados, inclusive como denuncia de descaso, já que a soma parecia ser vultosa para a época. Sugere o autor da carta que, a permanecerem os jardins em abandono, sem fiscalização direta da seção de obras do município, era preferível transformá-los em jardins públicos de passeio, com arvoredo e vegetação agradável ou, então, entregá-los à fiscalização direta dos subintendentes dos distritos, que por estarem mais perto poderiam melhor reparar por esses logradouros públicos.

Lendo esta carta, entretanto, uma referência nos chamou muito a atenção. $\mathrm{Na}$ tentativa de responsabilizar alguém pelo abandono em que se encontravam as praças, o autor traz revelações que nos fazem transcrever parte deste texto:

[...] O [jardim] de São João, que tem o nome de Pinheiro Machado, está completamente abandonado e o da Florida não reúne mais a multidão de creanças que antes ali passavam horas na mais pura alegria, dos rapazes e das meninas que, com os seus torneios de "baskett-ball"e "volley-ball" faziam o encanto do local. Antes, duas ou três vezes por semana era a praça aberta a noite, até ás 9 ou 10 horas, para que se entregassem os seus freqüentadores aos torneios desportivos. Agora nada mais disso há, porque um senhor com cara e modos de extrangeiro, que diz ser o director, parece ter embirrado com a petizada. [...] Com um pouco de animação, por não ter sido attingido pela birra do director, há o jardim do Alto da Bronze, mas esse mesmo já não reúne, como noutros tempos, o enthusiasmo dos seus freqüentadores - jornal Diário de Noticias, s/d (Álbum de artigos do acervo do CEME/ESEF/UFRGS, s/d).

Neste trecho podemos observar - além de uma reclamação quanto a manutenção estrutural do espaço físico - uma reclamação pessoal. É fato que a conservação não era a mesma do período inicial da instalação das Praças de Desportos. Mas também o descaso que tomava conta dá características de abandono por parte da municipalidade que tinha nestas praças até pouco tempo tanto apreço. 
Sendo a municipalidade representada pelo diretor das praças e Jardins de Recreio, também responsável pela organização e desenvolvimentos das atividades locais, entendemos que esta reclamação estava voltada ao Professor Gaelzer, ratificada pela frase "senhor com cara e modos de estrangeiro". O que podemos entender nesta afirmação é que as características físicas da etnia alemã do Professor Gaelzer eram citadas para identificá-lo na carta, como imigrante alemão ou descendente destes (teutobrasileiros) justamente no período que precedia a "onda nacionalista" no Brasil (GERTZ, 1991). Nesta época intensificavam-se os discursos questionadores das diferenças culturais, que eram marcantes nos teuto-brasileiros em todo o território nacional. Apesar, cabe lembrar aqui, como já o dissemos anteriormente, que o Prof. Gaelzer era cidadão brasileiro, nascido em Novo Hamburgo no Rio Grande do Sul.

Mesmo assim, apesar desta condição de teuto-brasileiro, portador dos “modos de estrangeiro" reconhece o autor da carta o bom trabalho levado a efeito nas Praças de Desportos. De fato, quanto aos procedimentos e atitudes do Prof. Gaelzer, não relata a carta uma discordância as regras em vigor neste período.

$\mathrm{Na}$ carta consta ainda referência aos momentos de alegria em que moças e rapazes passavam nas praças disputando torneios de basquetebol e voleibol realizados à noite, até ás $21 \mathrm{~h}$ ou mesmo até $22 \mathrm{~h}$, duas ou três vezes por semana, encantando aos que assistiam. Torneios estes que aconteciam nas praças conforme registro em um dos convites para a Festa da Primavera que destacava as competições entre o team da praça e o colégio Paula Soares.

A organização com que se davam as atividades nas praças também ficou registrada nos programas impressos que eram elaborados com um roteiro sobre os acontecimentos naquele dia aprazado. Encontramos um exemplo no programa de um 
dos eventos realizados nas Praças de Desportos. Na descrição deste programa as atividades que seriam voltadas aos menores, meninos e meninas, foram relacionadas como corrida em 75 metros, capitão soldado ladrão, corrida em pneus, jogo das batatas, circulo, salto em distancia, cabo de guerra.

A categoria de "rapazes" com atividades já voltadas aos moldes esportivos como corrida em 100 metros, salto em distancia, lançamento de bola, entre outras. E a categoria de "senhoritas" com corridas de agulhas e de velas, descrição condizente a preservação de sua feminilidade, apesar da prova. Todas estas eram sempre dedicadas em homenagem a nomes de expressividade na cidade. Fato interessante é que, nestes programas impressos as dedicatórias sempre vinham seguidas de um do nome a honrar.

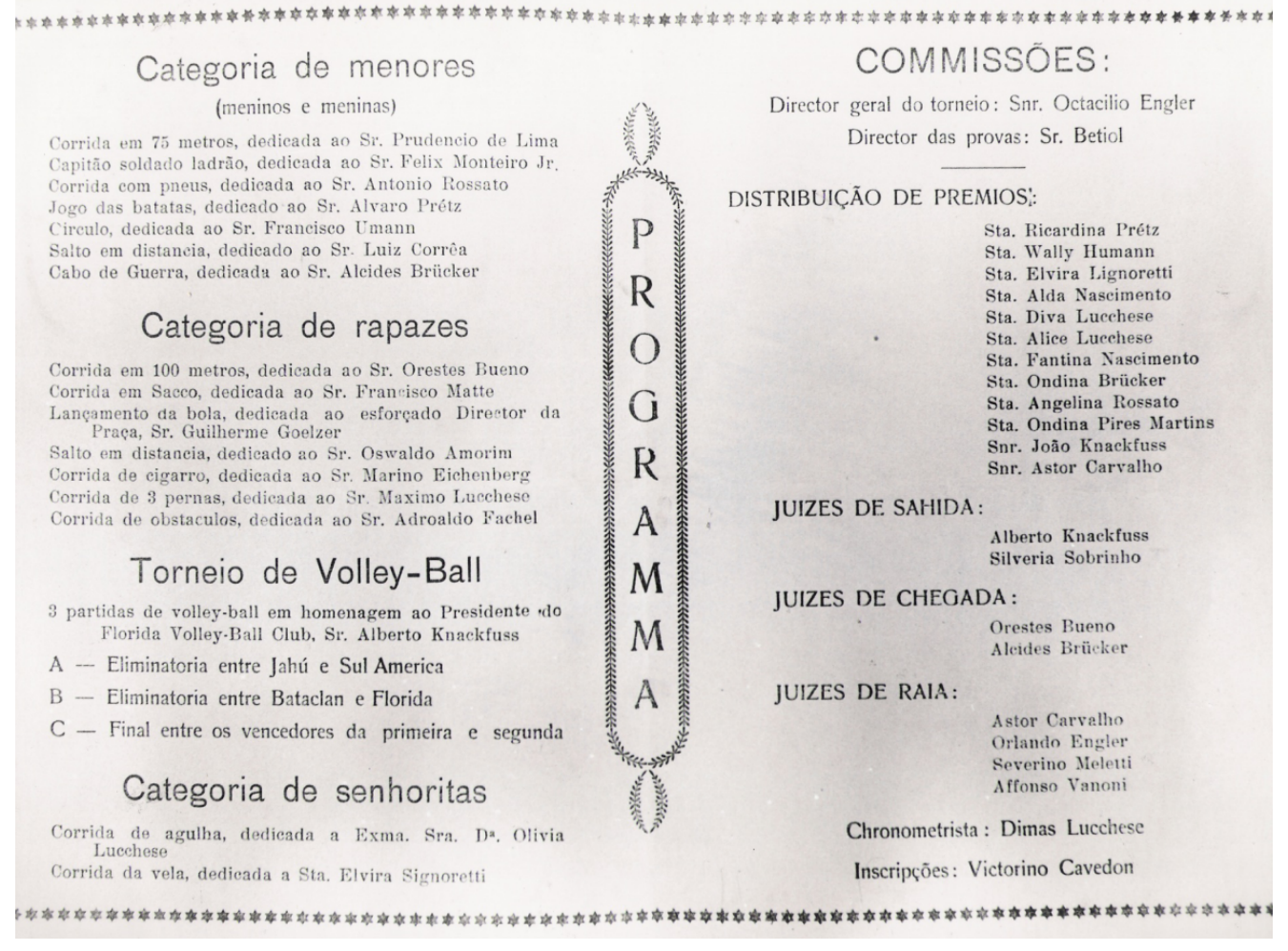

FIGURA 2 - Programa das atividades realizadas no Jardim de Recreio Florida, s/d.Fonte:CEME/ESEF/UFRGS. Pasta-arquivo sob titulo Recreação Pública.

Chamamos atenção neste roteiro para a modalidade para rapazes "lançamento de bola" onde encontramos entre os homenageados a frase: "dedicada ao esforçado 
Director da Praça, Sr. Guilherme Gaelzer". Mas a carta ainda nos guarda uma importante informação quando diz que o Professor Gaelzer ficou "embirrando com a petizada" privilegiando alguns freqüentadores quanto à utilização dos espaços esportivos da praça. Salientamos isto, pois constatamos que existia uma intenção clara do Professor Gaelzer em estimular a formação de equipes para competição nas praças, pois desde o primeiro ano de exercício as praças já eram representadas por suas equipes em competições interpraças.

Um claro exemplo desta intenção se dá quando pela iniciativa do Professor Gaelzer foi organizado o Campeonato Municipal de Volley-Ball na cidade disputado em duas categorias, de rapazes e moças. Poderiam ter inscritos em cada praça uma equipe somente e por este motivo foram realizadas eliminatórias entre os Jardins de Recreio, a fim de ser apurado o campeão de cada praça, o qual disputaria a prova final no campeonato municipal. Aquilatamos a importância deste evento quando encontramos em publicação de jornal a menção sobre a entrega da premiação aos vencedores com a presença do Intendente Municipal Dr. Octavio Rocha:

Aos vencedores, a municipalidade offerecerá uma taça, que será entregue pelo Dr. Octavio Rocha, intendente municipal, no dia do encerramento do campeonato que será no jardim de recreio "Dr. Montaury" (Álbum de artigos do acervo do CEME/ESEF/UFRGS, s/d).

Entre os eventos esportivos realizados nas praças e citamos: Campeonato Popular de Basquete (1938); Torneio Universitário de Football (1938); Torneio de Vôlei Feminino (1940); Grande Corrida Rústica "Semana da Pátria" (1939); Torneio de Basquete e Vôlei da Praça Dr. Montaury (1938) e Programa de Recreação na Praça Pinheiro Machado em homenagem aos garotos vendedores de jornais (1938/1939) (PIMENTEL, 1945; MAZO, 2005). Estas diversas competições nos remetem ao entendimento de que as praticas corporais e esportivas constituídas como modernas 
atividades de lazer cumpriam seu papel liberando as tensões do estresse cotidiano, permitindo as manifestações de sentimentos guardando a integridade física e moral das pessoas dentro da ordem imperante (ELIAS \& DUNNING, 1992).

O que se pode ver até aqui é que, de um espaço destinado para o lazer e recreação de todos - concepção original das Praças de Desportos e dos Jardins de Recreio - começava a forjarem-se espaços para a formação de atletas que sediados em suas praças, nelas treinavam e a elas representavam. Um indício que nos fará buscar num próximo artigo, respostas para a possibilidade de, a praça de todos, ser apropriada e se tornar a praça de alguns.

As representações estão associadas no imaginário coletivo, onde grupos, para ganharem espaço e poder, produzem estratégias, discursos e idéias que têm ressonância no universo cultural e grande força de persuasão e convencimento. Assim, fica para nós a idéia de um local onde o simples fato de ali "estar" significava "ser" parte da história das representações corporais que por ali se descortinaram. A aparição expressiva deste momento histórico para a cidade foi abordada na esperança de levantar a ponta de um véu que com maior dedicação poderá ser ainda estudado.

\section{CONSIDERAÇÕES FINAIS}

Identificar como foi construída, pensada, dada a ler, a realidade social da cidade de Porto Alegre nos anos de 1920 a 1940 no que diz respeito às práticas corporais e esportivas nas praças públicas era nosso objetivo neste estudo. Porto Alegre, no período de 1920 a 1940, passou por um processo de remodelação urbana sem precedentes. Novas avenidas, crescimento comercial e industrial, campanha moralizadora, novos 
cafés, Rua da Praia, novos costumes e o a difusão das práticas corporais e esportivas. Numa verdadeira época do "novo" a modernidade ditou as normas de conduta, instaurando um tempo de ameaça e sedução.

A ordem burguesa que tinha nos footings na Rua da Praia seu espaço de visibilidade começa a ver surgir nos espaços públicos das praças e parques públicos da cidade de Porto Alegre as novas práticas corporais e esportivas. Estas práticas foram introduzidas nestes espaços, inicialmente, com a instalação dos Jardins de Recreio. Estes eram espaços compostos de praças de brinquedos infantis e quadras esportivas tinham seu ponto forte na organização de suas atividades resultando em utilização de seus espaços por crianças, jovens e adultos. Organização que se submetia a municipalidade, através da institucionalização do Serviço de Recreação Pública, e que teve no professor Frederico Guilherme Gaelzer um precursor e defensor.

Junto aos Jardins de Recreio ficavam as "Praças de Desporto" onde os campeonatos de voleibol, basquetebol, corridas e atividades de recreação, entre outras, tomavam as praças na modernização dos hábitos e costumes dos porto-alegrenses com grande assistência e participação.

Os porto-alegrenses se habituaram a ver nestas demonstrações o espírito esportivo exaltado e uma disciplina necessária para um futuro promissor de crianças, de jovens, da pátria, de todos. Elas se vinculavam à idéia da importância do fortalecimento físico, mental e moral dos seus praticantes para o crescimento do Brasil. Esses princípios possibilitam entender estas práticas como um mecanismo de identidade neste contexto histórico.

As representações culturais de uma identidade construída nas praças públicas da cidade de Porto Alegre através das práticas corporais e esportivas nos anos de 1920 a 
1940 revelam que estas foram resultado de uma relação de força entre as representações impostas pelos que detinham o poder e a capacidade de resistência ou de aceitação, que a comunidade produziu de si mesma. As práticas nos deixam ver e reconhecer uma identidade social, pois nos permite assistir uma maneira própria de ser no mundo, e significar simbolicamente um estatuto e uma posição; enfim, as formas institucionalizadas e objetivadas em virtude das quais representantes (instâncias coletivas ou indivíduos singulares) marca de modo visível e perpétuo a existência do grupo, da comunidade ou da sociedade.

Assim do olhar que dirigimos a antiga Porto Alegre, no desenvolvimento deste trabalho, fica a expressividade com que estas representações culturais de identidade através das práticas corporais e esportivas do período manifestaram-se, a ponto de nos fazer reconhecer sua existência e chamar a nossa atenção. Era nosso dever revelar o que encontramos até aqui, e mostrar o caminho para quem queira ir ainda mais além. Fica para nós um sentimento de agora sermos também parte desta história pelo simples fato de ter para ela olhado, para contar esta nossa versão.

\section{REFERÊNCIAS}

AMARAL, S. Lazer/Recreação: estudos de memória na cidade de Porto Alegre - uma proposta em andamento. Licere, Belo Horizonte, v.2, n.1, 1998.

AMARAL, S. Espaços e vivências públicas de lazer em Porto Alegre: da consolidação da ordem burguesa à busca da modernidade urbana. Revista Brasileira de Ciências do Esporte, Goiânia, v. 23, n. 1, set. 2001, p. 109-121.

BARDIN, L. Análise de Conteúdo. Lisboa: Edições 70, 1977.

BURKE, P. O que é história cultural? Rio de Janeiro: Jorge Zahar Ed., 2005.

CARDOSO, C. Uma introdução à história. 9. ed. São Paulo: Brasiliense, 1992. 
CASTRO, M. Relatório do Projeto Publicidade na Revista do Globo. PUC, Rio Grande do Sul, 1999. Faculdade de Comunicação Social, PUCRS. Porto Alegre, 1999.

CHARTIER, R. A história cultural: entre práticas e representações. Lisboa: DIFEL, 1990.

O Mundo como representação. Revista de Estudos Avançados. São Paulo, v. 11, n. 5, 1991, p. 173-191.

DALMÁZ, M. A imagem de Hitler e da Alemanha na Revista do Globo de Porto Alegre: 1933-1945. Dissertação 9Mestrado) - Programa de Pós-Graduação em História, PUCRS, 2001.

ELIAS, N. Sobre el tiempo. México: Fondo de Cultura Económica, 1989.

A Sociedade dos indivíduos. Rio de Janeiro: Zahar, 1992.

\& DUNNING, E. A busca da excitação. Lisboa: Diefel, 1992.

O processo civilizador. Rio de Janeiro: Zahar, 1994.

FEIX, E. Lazer e cidade na Porto Alegre do início do século XX: a institucionalização da recreação pública. Dissertação (Mestrado) - Programa de PósGraduação em Ciências do Movimento Humano. UFRGS. Porto Alegre, 2003.

GAELZER, L. Recreação pública em Porto Alegre: evolução histórica. Porto Alegre: UFRGS, 1975.

GAELZER, F. Álbum particular de recortes de artigos. CEME/ESEF/UFRGS sem ficha catalográfica. $\mathrm{s} / \mathrm{d}$.

GERTZ, R. O perigo alemão. Porto Alegre: Editora da UFRGS, 1991.

GOMES, L. Ernst Zeuner: artista designer. Dissertação (Mestrado) - Faculdade de Comunicação Social, PUCRS. 2001.

GOMES, C. Significados da recreação e lazer no Brasil: reflexões a partir da análise de experiências institucionais (1926-1964). Tese (Doutorado) - Faculdade de Educação, Universidade Federal de Minas Gerais, 2003.

GUTIERREZ, W. Disponível em: 〈http://www.esef.ufrgs.br/historico.php〉.

LÜDKE, M. \& ANDRÉ, M. Pesquisa em educação: abordagens qualitativas. São Paulo: EPU, 1986.

MACEDO, F. Porto Alegre, história e vida da cidade. Porto Alegre: Editora da Universidade/UFRGS, 1973.

MAZO, J. O lazer na cidade de Porto Alegre. In: DACOSTA, Lamartine (Org.). Atlas do Esporte no Brasil. Rio de Janeiro: Shape, 2005. 
MAZO, J. Catálogo do Esporte e da Educação Física na Revista do Globo (19291967). Porto Alegre: PUCRS, 2004, CD-ROM.

MOTTIN, A.; MOREIRA, A. (Org.). Catálogo Literário da Revista do Globo. Porto Alegre. Base de dados desenvolvida em software Micro-ISIS, de propriedade da UNESCO, v. 3.07, 1996.

PESAVENTO, S. Indagações sobre a História Cultural. Artcultura Revista do Nehac, Uberlândia, v. 3, n. 3, p. 9-15, 2002.

PIMENTEL, F. Aspectos gerais de Porto Alegre. Porto Alegre: Imprensa Oficial, 1945.

SILVA, L. A chama que arde em nossos clubes! A Corrida de Revezamento do Fogo Simbólico da Pátria em Porto Alegre (1938-1947). Dissertação (Mestrado) Programa de Pós-Graduação em Ciências do Movimento humano, UFRGS, 2008.

SOARES, L. Gênero e poder na Revista do Globo. Monografia (Graduação) Comunicação Social, PUCRS, 2001.

STIGGER, M. Administração de parques públicos e democracia: um estudo de caso na área de políticas publicas para o lazer na perspectiva democrática. In: Revista Brasileira de Ciências do Esporte. São Paulo v.15, n.1, p. 66, set.1993.

THORSTENBERG, V. Página de Rosto: uma amostra do potencial literário da Revista do Globo. Dissertação (Mestrado) - Programa de Pós-Graduação em Letras, PUCRS, 1998.

TORRESINI, E. Editora Globo: uma aventura editorial nos anos 30 e 40. Porto Alegre: Editora da USP; Editora da UFRGS, 1999.

TRIVIÑOS, A. Introdução à pesquisa em ciências sociais: a pesquisa qualitativa em educação. São Paulo: Editora Atlas, 1992.

WERNECK, C. Lazer e Estilo de Vida. In: BURGOS, M. \& PINTO, L. (Org.). Recreação, lazer e estilo de vida no Rio Grande do Sul: refletindo sobre algumas ações desenvolvidas na capital gaúcha no período 1926-1978. Santa Cruz do Sul: EDUNISC, 2002.

\section{Endereço dos Autores:}

Maria Luisa Oliveira da Cunha

Av. Cel Lucas de Oliveira, 2588/201

Bairro Petrópolis - Porto Alegre - RS

CEP: 90460-000

Endereço Eletrônico: maluoliveira@terra.com.br 